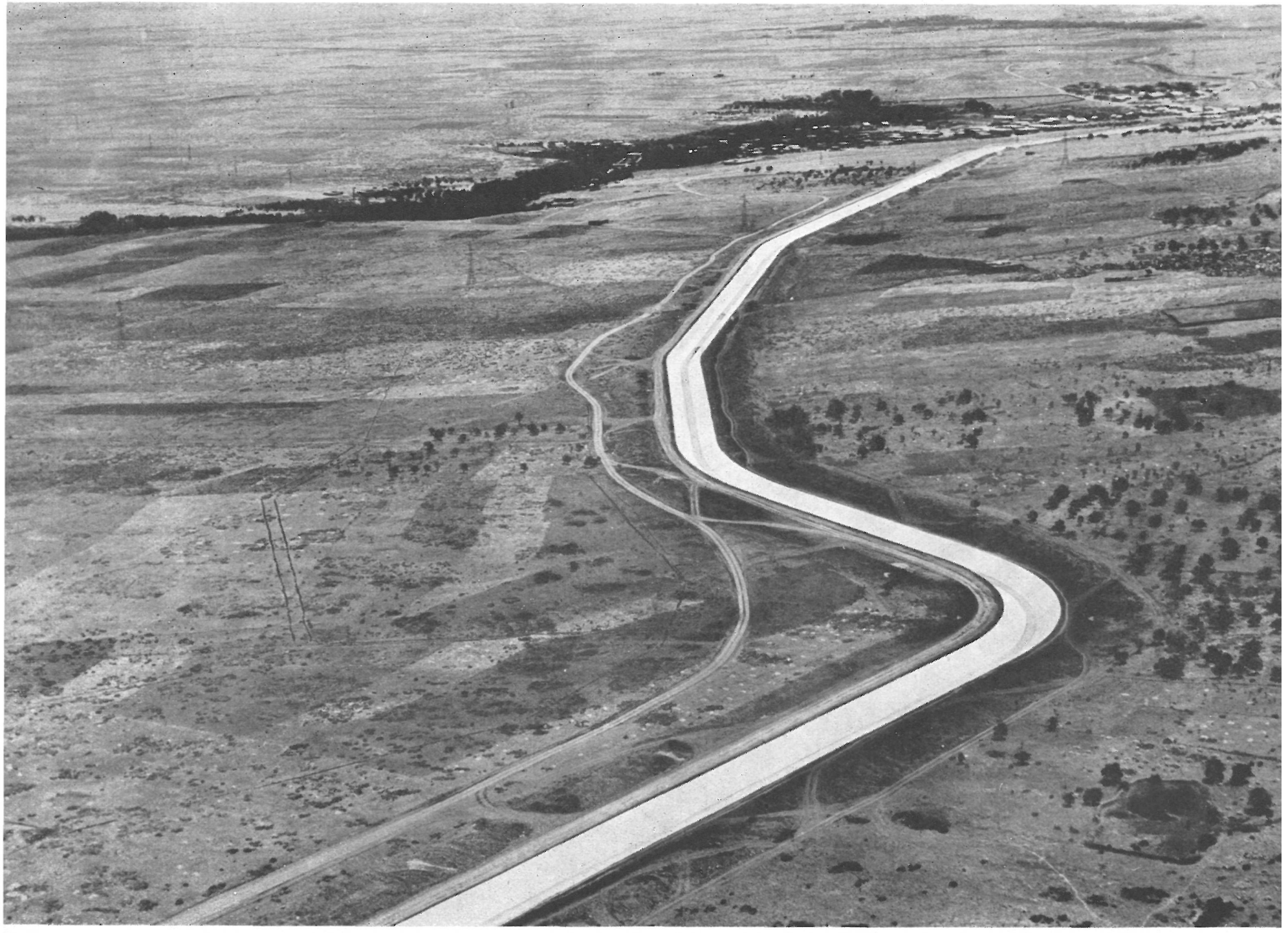

\title{
revestimiento de canales
}

A. WOLL, ingeniero

$866-12$

La maquinaria moderna alemana empleada para el revestimiento de canales de gran sección, presenta grandes ventajas de economía, rendimiento, regularidad e impermeabilidad de la construcción. Para la aplicación de esta maquinaria-inicialmente se ha procedido a la excavación del canal mediante el empleo de maquinaria ordinaria de desmonte y la maquinaria especial-comienza su trabajo con el enrase de las cotas previstas.

La máquina niveladora empleada en el enrase del canal lateral tel río Rhin, en las obras hidráudicas de Ottmarsheim, cuya potencia es de $110 \mathrm{CV}$, ha dado un rendimiento diario del orden de 1.500 a $2.000 \mathrm{~m}^{2}$ de superficie nivelada. La 


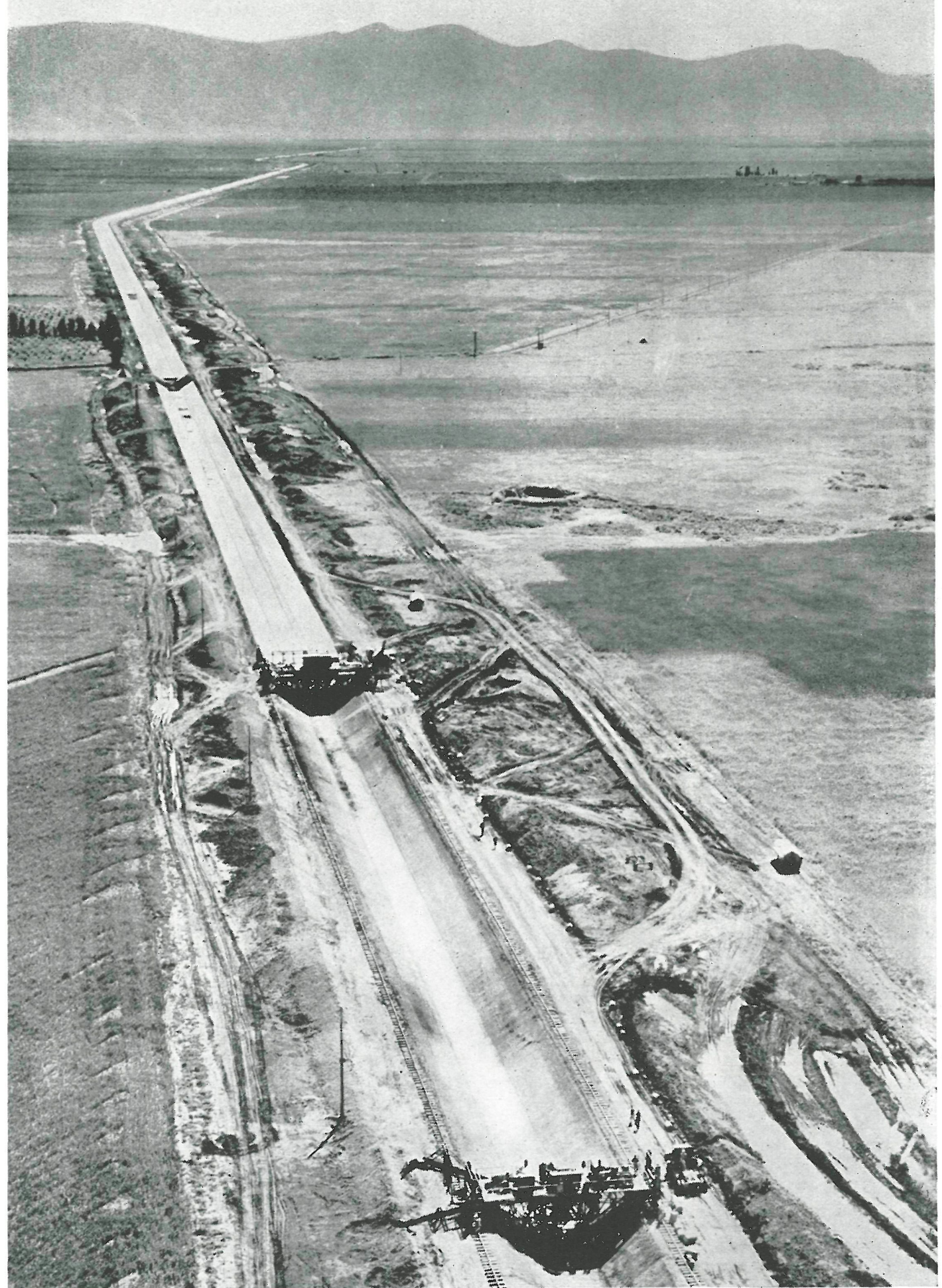

\begin{tabular}{l}
1 \\
0 \\
$=$ \\
$=$ \\
$x$ \\
2 \\
0 \\
0 \\
-1 \\
0 \\
1 \\
\hline 0 \\
0 \\
0 \\
$E$
\end{tabular}

máquina consiste, en esencia, en un rodete móvil, provisto de un juego de paletas, colocadas al tresbolillo, que van excavando y vertiendo los materiales arrancados sobre una cinta transportadora que vacía sobre una tolva, de la que se cargan los camiones que transportan el escombro.

En las obras del referido canal se han revestido los taludes, utilizando una maquinaria hormigonera, de $75 \mathrm{CV}$ de potencia y con capacidad de trabajo de 1.000 a $1.200 \mathrm{~m}^{2}$ de superficie revestida por jornada. Su mecanismo esencial consiste en un carro móvil, provisto de una tolva para la alimentación de hormigón; una chapa distribuidora, de sección en forma de segmento poligonal, y un dispositivo de acabado, montado inmediatamente después de la chapa de distribución del hormigón. 
Existen también hormigoneras especiales para revestimientos de hormigón de hasta $50 \mathrm{~cm}$ de espesor. Este tipo de máquina va provisto de un sistema vibrante, que se ha montado en la parte posterior de la tolva, y distribuidora del hormigón.

Cuando los taludes presentan una gran altura, como ocurre en la presa de Reisach-Rabenleite. donde la longitud de talud según la línea de máxima pendiente es de $28 \mathrm{~m}$, se puede subdividir la superficie de hormigonado en cuatro bandas de $7 \mathrm{~m}$ cada una, con lo que se reduce notablemente la luz del puente que forma la máquina lo que permite disminuir las flechas accidentales de la pluma, que es más ligera y permite obtener superficies más regulares.

El trabajo por bandas parciales no presenta grandes dificultades, pues basta ir corriendo las vías de apoyo a medida que se cambia de banda.

En el Marruecos francés se han realizado gran número de obras de revestimientos de canales de mediana sección, utilizando un sistema continuo de cuatro máquinas que trabajan en cadena, una tras otra, en el orden siguiente: 1. Máquina niveladora; 2. Hormigonera; 3. Formación de juntas, y 4. Máquina auxiliar.

Para trabajar racionalmente empleando estos procedimientos de máquinas en serie, se necesita un estudio previo de los aprovisionamientos de aglomerantes y áridos, ya que la velocidad de avance es grande y debe existir un cierto sincronismo entre las distintas máquinas operantes.

Las juntas suelen formarse según dos procedimientos distintos: 1. Se $^{\circ}$ pueden abrir en el hormigón aún fresco, por medio de cuchillas vibrantes que entran parcial o totalmente en el hormigón. Otro procedimiento consiste en cortar el hormigón, al cabo de cuarenta y ocho horas, por medio de muelas refrigeradas con un chorro abundante de agua.

Los resultados obtenidos con la aplicación de esta maquinaria han sido notablemente satisfactorios, siempre, claro está, que la obra tenga suficiente longitud o superficie para compensar los gastos de instalación.

Máquina niveladora del talud.

Puente para el hormigonado del revestimiento.

Puente de hormigonado para grandes espesores.

Hormigonado de taludes por bandas sucesivas.
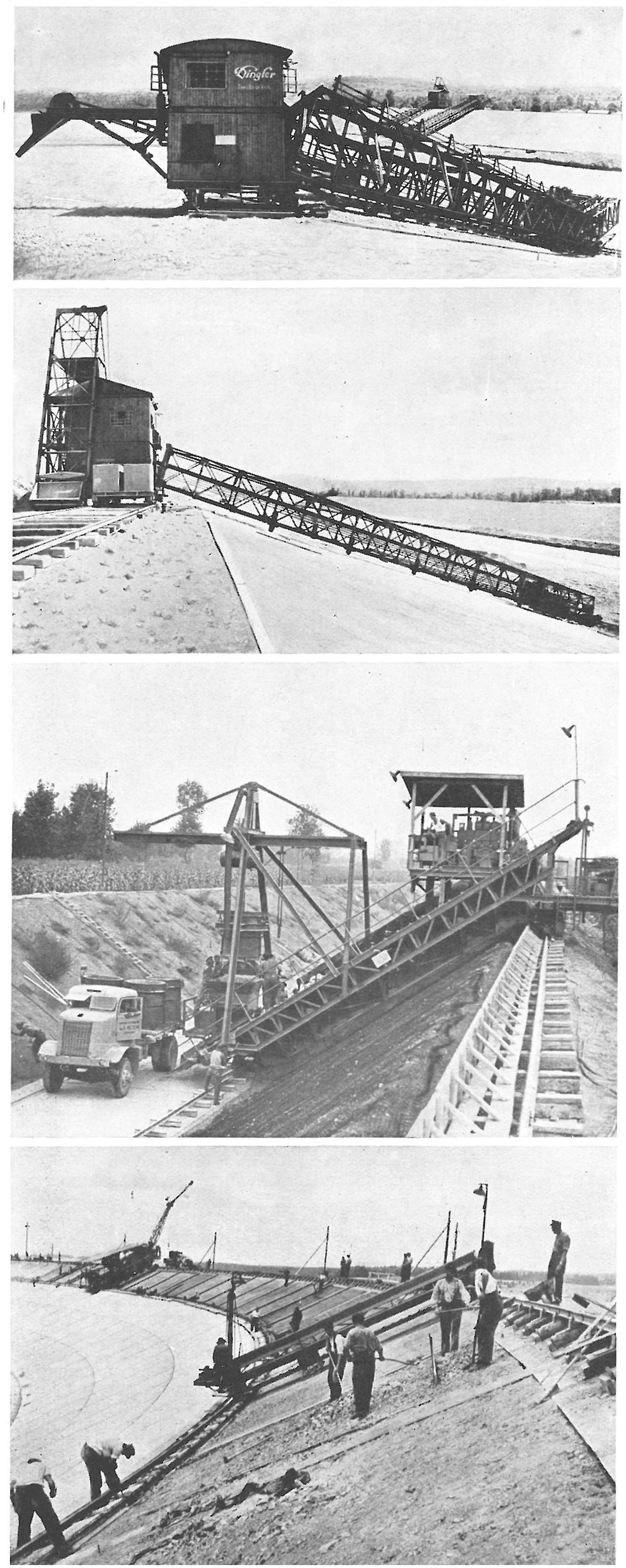